\title{
Reproductive technologies and the family in the twenty-first century
}

\author{
Daniela Cutas and Anna Smajdor
}

The first IVF baby was born in 1978 in the UK, following an intervention that had not been preceded by any clinical trials. After Louise Brown's birth, legislators and policymakers rushed to create an ethico-legal framework within which this new development could be practised without outraging public sensibilities. Since then, the speed and direction of scientific research as well as the practice and regulation of reproductive technology have been inexorably shaped by assumptions concerning family, fertility and reproduction. Research towards ever more sophisticated medical technologies for the purpose of the relief of infertility has raised relatively few concerns, provided the procedures were proven to be satisfactorily safe, and insofar as they were used to facilitate and reinforce existing norms about family structure and relationships. Ideas of what a family is (or should be) have a powerful influence on determining which potential technological innovations in human reproduction are developed and funded, and who can access them.

Social, legal and biological parenthood did not invariably coincide in the past. Different jurisdictions have various approaches to the ascription of parental rights and responsibilities. However, the default legal position is that a woman who gives birth to a child is that child's mother and her husband is the father - regardless of whether she is the genetic mother or he the genetic father. Embedded in this view is the expectation that the two members of the married couple are the legal and social parents and also the biological parents of the child. These legal measures have not been extended in the same way to the case of same-sex married couples. Furthermore, the child's 'right to know' her genetic origins, which features as a core argument for transitioning from anonymous to non-anonymous gamete donation in many countries, has not persuaded legislators that children who are born to married couples via sexual reproduction should also be aware of who their genetic father is (Ravelingien and Pennings 2013). These assumptions indicate that biological relationships are subservient to the nuclear family in the eyes of the law - and 
furthermore, specifically to the heterosexual nuclear family (Cutas and Chan 2012).

Developments in reproductive technologies have created new types of connections. A woman can now give birth to a child who is not genetically her own, or to a child who bears genetic material from both herself and another woman (via, for example, mitochondrial DNA transfer). Perhaps, in the future, a woman will be able to give birth to a child who is only her own genetically (via solo reproduction with in vitro-created gametes or human cloning). Gamete donation and surrogacy bring about challenges that many legislatures are still trying to sort out. Changes brought about by such innovations are increasingly hard to reconcile with still pervasive nuclear family expectations in ethics and regulation. If not so long ago, legal parenting at least approximately mirrored genetic parentage (one female mother and one male father, preferably married to each other), the diversification of genetic parentage itself, alongside a host of other sociocultural changes, pushes the model further into what some have called the crisis of the family (Collier 1999: 38-58; Cutas and Chan 2012; Szczurek 2013: 355-90).

In this chapter, we explore the nature and significance of these interactions in the context of research towards prospective reproductive technologies. We will start by giving a brief overview of the aftermath of the advent of IVF in the UK. We will then discuss how desires come to be classified as medical needs, and the relation between reproductive aspirations, the circumstances of those who hold them, and the weight that they are given. This will lead us to a discussion of current definitions of infertility, which have constituted the core criteria of access to reproductive technologies. These definitions determine not only who has access to reproductive technologies, but also whose desires are deemed worthy to motivate research efforts to make these treatments possible.

\section{The regulatory background in the UK}

After Louise Brown's birth was reported in the British press, amid much speculation and anxiety about the likely effects of IVF, the government of the time concluded that some regulatory intervention would be required. The public needed to know that scientists' and doctors' activities were subject to ethical and legal oversight (Deech and Smajdor 2007). A report into the ethics of IVF and embryo research was commissioned: its task was to answer the question of whether the use of IVF was acceptable and if so, in which circumstances - and to advise on the acceptability of using human embryos in research. Mary Warnock, the chair of the committee, held the position that legal and regulatory barriers need not be based solely on the avoidance of adverse consequences. Rather, she claimed that these barriers reflected a public desire for boundaries, 
and served to express and enforce moral beliefs that define our social identity:

[i]n recognising that there should be limits, people are bearing witness to the existence of a moral ideal of society. (Report of the Committee of Inquiry into Human Fertilisation and Embryology 1984: 2)

A society which had no inhibiting limits, especially in the areas with which we have been concerned ... would be a society without moral scruples. And this nobody wants. (Report of the Committee of Inquiry into Human Fertilisation and Embryology 1984: 2) [our emphasis]

Barriers, it is generally agreed, must be set up. (Report of the Committee of Inquiry into Human Fertilisation and Embryology 1984: 3)

While later reports were critical of Warnock's approach, and less enthusiastic about the importance of barriers (House of Commons Science and Technology Committee 2004-05: 4-5), it remains the case that the direction of scientific progress, and the form of the post-reprotec family, have been profoundly shaped by these regulatory constraints. Since the UK's legislation in this context formed a blueprint for many other countries (Rasmussen 2004; Bennett 2008), its assumptions and the barriers based on them have had an impact worldwide on what can and cannot be done with reproductive technology.

The Warnock Report was published in 1984. Marriage and couples feature extensively in its pages. Although considering arguments in favour of individual women and men who might wish to become parents with the help of reproductive technologies, the Committee members held the belief 'that as a general rule it is better for children to be born into a two-parent family, with both father and mother' (Report of the Committee of Inquiry into Human Fertilisation and Embryology 1984: 11-12). The legislation based on the Warnock Report's findings, the Human Fertilisation and Embryology Act, was not passed until 1990 (subsequently amended in 2008). Globally, IVF and related techniques had grown and proliferated during this period, opening many new possibilities that had not been envisaged previously. In view of this, it is not all that surprising that some think the Act was already outdated almost from the moment it became law (Lee and Morgan 2001: 2). Many new and prospective avenues for scientific and medical exploration, such as surrogacy, pre-implantation diagnosis, mitochondrial donation, egg freezing and the possibility of creating gametes in vitro, were emerging. The latter is of particular interest because prospective innovations such as in vitro-created gametes or human cloning may disintegrate the biological boundaries that currently help to define what we mean by reproduction (Hendriks et al. 2015).

However, the regulatory framework is only part of the story here. Another issue is medicine itself. From its very earliest days the relationship between reproductive technology and medicine has been uneasy and fraught with 
controversy. The legislative framework gives a broad overview of what can and cannot be undertaken in a general sense. But the medical establishment determines which patients are eligible for treatment - and which needs require medical intervention or research into the development of future treatment options. As we will show, the clinical basis for these is very far removed from many other areas of medicine. Although the use of reproductive technologies is thought of and presented as 'treatment' for infertility, very often the patient may be in perfect reproductive health, but have a partner who has fertility problems - or simply not have succeeded to become a parent in the natural way with a specific partner. In reproductive medicine, one person can be the vehicle by which another person's medical problem is addressed. Moreover, the aim of treatment is not to remedy the fertility problem (through repairing fallopian tubes, for example) but to provide people with a baby. This means it is not always easy to see what makes one procedure a legitimate medical treatment, and not others.

IVF is accepted in many countries across the world as a legitimate - and on the whole a morally acceptable - means of treating infertility. Reproductive cloning, on the other hand, is stringently forbidden almost everywhere in the world, and is regarded by many as being morally abhorrent (Wellcome Trust 1998). Yet both IVF and reproductive cloning are techniques which could enable a person to have genetically related offspring. Interestingly, surveys of public views about the permissibility of reproductive cloning indicate that cloning is felt to be more acceptable if it is presented as an option for a heterosexual couple (as opposed to e.g. a single individual) (Shepherd et al. 2007). That is, it is the perception of a technology as a means of reproducing the nuclear family which seems to facilitate its acceptance - while at the same time what counts as a medical problem depends upon how close one's circumstances are to the preferred relationship form.

Normative assumptions about family structure are also mirrored in medical practice and in regulatory approaches to fertility treatment. In many countries, access to treatment depends heavily on the degree to which the patient matches a specific relationship and/or family model. Fertility treatment is more readily accepted when it facilitates the creation of nuclear families. This is still how things are in many jurisdictions: though more and more exceptions are made. For example, in the Netherlands, single women are often refused treatment. Those who do receive treatment are required to undergo psychological tests (Pieters 2015). In Sweden, female same-sex couples only acquired the right to access fertility treatments in 2005, and single women in 2016. As we will see further on in this chapter, in Italy (Legge 40, 2004) and France (Loi n ${ }^{\circ}$ 2011-814) only heterosexual couples are allowed access. This means that although different sets of individuals may have a similar desire - to have a child - that desire is more likely to be construed as a legitimate medical need when the individual is in a partnership with someone from the other sex. Similarly, when we look at access to uterus transplantation, we can see that while many people may 
have the desire to gestate a baby in their own body, only those who fit certain norms can access treatment that would enable them to do so.

\section{Reproductive needs and the nuclear family}

Reproductive technologies tend to be allowed to operate only within boundaries that are perceived to replicate or repair the natural. Sheila Jasanoff notes that

genetic engineering threatens or calls into question many of the categories that have been accepted as foundational in the ordering of societies, both ancient and modern. These include the fundamental divisions between nature and culture, moral and immoral, safe and risky, god-given and human-made.

(2005: 26)

The ways in which reproductive technologies are regulated illustrate some attempts to limit their 'disruptive potential', to keep them within conceptual boundaries that match certain norms about what constitutes the family. In what follows we will show how, if we look for the reinforcement of concepts of nature and biology in the family, we can see how deeply entrenched these ideas are, and how powerful a role they play in managing the potential threats inherent in new technologies. Nuclear families in this context are not necessarily favoured for overtly political or even moral reasons, but because they represent a natural or biological norm. As Barrett and McIntosh put it:

It is in the realm of gender, sexuality, marriage and the family that we are collectively most seduced by appeals to the natural. In this realm the shifting norms of practice are solidified, some to be sanctified and others condemned. The prevailing form of family is seen as inevitable, as naturally given and biologically determined. (1991: 27)

This 'naturalness' of the nuclear family form has been contested by researchers from various angles (Stacey 2011; Diduck and Kaganas 2012). It is clear that when the nuclear family is used as the measure of how things should be, this will have an impact on what research is encouraged and seen as responding to a legitimate need. This has already been seen in the case of IVF. It seemed evident to the Warnock Committee that IVF's primary use should be to facilitate the formation of nuclear families. They foresaw that single women or perhaps lesbian couples might want to use IVF with sperm donation and in doing so, to create children who would be raised without a father. In an effort to circumvent this, a clause was included in the law governing fertility treatment, requiring clinics to 'consider the need of a child for a father'. Effectively, this gave clinics grounds for refusing single women and lesbian couples, since fertility doctors had a legal obligation to consider the welfare of the future child, and since this welfare consideration was explicitly linked with the need for a father. In 
this way, the primacy of the nuclear family was protected, at least to some degree.

It is clear that genes play a very important part in our understandings of reproduction. However, although genetic connections are often viewed as being determinative of parenthood, as we will see further in this chapter when we discuss mitochondrial DNA transfer, it is now becoming possible to ask whether a genetic link is either necessary or sufficient to justify calling a child one's own 'biological' offspring (Barritt et al. 2001). Following from this, we can ask whether any or all technologies which can produce children genetically related to some specific individual should be categorised as fertility treatments. For example, the World Health Organization (WHO) (1998) described reproductive cloning as replication rather than reproduction and stated that because it was not reproduction it should therefore be prohibited. Human reproduction, it has been argued, is essentially collaborative and sexual, while cloning is not sexual and can be non-collaborative, and thus is more akin to manufacture than reproduction (National Bioethics Advisory Commission 1997). The relationship between genes, parenthood and reproduction also feeds into the categorisation of certain technological possibilities as being therapeutic, curative, or needs related. Many people want babies related to them in particular ways, but only some of these people are deemed to have needs that can or should be addressed through medical technology. For example, same-sex male couples and single men cannot access treatment in the UK or in Sweden, because of the illegality of surrogacy. A number of countries impose strict cut-off ages for women wishing to access treatment. Denmark, Belgium and the Netherlands permit IVF only for women who are under 45, while France requires that women must be 'of reproductive age' (Brigham et al. 2013). While the desire for a baby may be the same in all cases, only some people's desires are regarded as being suitable for fulfilment through medical treatment. The categorisation of desires as needs often follows a particular kind of a biological model, so that although we use technology to supersede and transcend biology in various ways, other possibilities are marked off as taboo.

An interesting example of the relationship between genes, family norms and research/treatment priorities is the case of mitochondrial DNA transfer. Those who seek this procedure may be at risk of transmitting a mitochondrial mutation to their children. This risk is removed when the mitochondrial DNA of the carrier prospective mother is replaced with another woman's. Using this technique, the resulting offspring inherits genetic material from three people: the woman who provides the nucleus of the egg, the woman who provides the mitochondrial DNA and the man who provides the sperm. The presence of DNA from three different people has made the technique controversial. It has often been referred to in the press as creating babies with three parents (Hamzelou 2016; Macrae 2016).

However, many scientists in the field insist the term 'three-parent baby' is inaccurate because the nuclear DNA used in the child's creation is still 
from two people only (Sample 2015). The manoeuvre to exclude the mitochondrial DNA contributor from the status of genetic parent makes it easier to construe mitochondrial DNA transfer as therapeutic. Rather than intervening to add genes or progenitors to a process that naturally involves only two genetic contributors, the addition of mitochondrial DNA is classified as 'mending' or 'replacing' a faulty part in the maternal egg. Thus, according to this approach, the child still has only one genetic mother and the process is acceptable as it is reconfigured to maintain our expectations of the biological norm: each child has exactly two genetic parents.

This reframing to angle the procedure away from anything as drastic as introducing a third genetic parent into reproduction has given the technique a kind of validation, and this enables the related research on which it is based to progress. This is achieved, however, by dint of redefining what we mean by genetic parenthood - a not insignificant development. The exclusion of one of the DNA contributors from parent status seems to open the possibility that genetic parenthood is a matter of degree, since the mitochondrial donor simply does not provide enough genetic material in relation to the other parents. While we do not seek to define genetic parenthood here, it is clear that the question of what constitutes a parent is one that is raised, rather than resolved, by the development of such techniques. Yet their permissibility seems to depend on the redefinition of parenthood so as to forestall this question.

Mitochondrial DNA transfer also opens up other possibilities for those who wish to have children in non-traditional families. For example, mitochondrial DNA transfer could be used to 'rejuvenate' the eggs of women who may already be past the optimal reproductive age. It has been suggested that replacing the mitochondrial DNA of the older woman's egg with that of a younger woman can 'improve' the quality of the egg, thus increasing the chances of a successful pregnancy (Reynier et al. 2001; May-Panloup et al. 2005; Wolf et al. 2015). However, the use of mitochondrial transfer for this purpose has to date not been licensed by the HFEA in the UK.

We have focused almost entirely on aspects of genetic parenthood. However, there are of course other ways in which people can become biological parents. One of these is gestation. Women who seek medical treatment in order to become mothers may value different aspects of motherhood differently. One might wish to transmit genes to her child, another might wish to mature the gametes in her own body following ovarian tissue transplant, while others might place a higher value on gestating a child. Again, these possibilities reveal differences in the way that the desires of some individuals are integrated into the discourse of medical need and treatment, while those of others are excluded. We will look here at uterus transplants as a particularly interesting example.

Children have recently been born after having been carried in a uterus transplanted into a woman from another woman (The Guardian 2015). The paradigmatic patient for this treatment is one who was born without 
a uterus. However, only a very specific subset of such individuals are selected to receive these transplants. Such transplants have been offered as part of a clinical trial. In this scenario, the boundary between therapy and research is blurred. For the women involved, their only chance of access to this treatment may be enrolment on the trial. Because regulations for research are tighter than those for standard treatment options, those undertaking the trials are able to impose narrower constraints on eligibility than might otherwise be the case.

According to one group of experts, the recipient must be 'a genetic female of reproductive age'. She must have 'a personal or legal contraindication to surrogacy and adoption'. Her wish to undergo uterine transplant must not be 'irrational'. She must not 'exhibit frank unsuitability for motherhood' (Lefkowitz et al. 2012). Another research group stipulate that to be eligible, patients must be:

- Women with AUI [absolute uterine infertility]

- Ages 20-35, with working ovaries

- BMI of less than 30

- Cancer free for at least 5 years

- Negative for HIV, hepatitis B and C, chlamydia, gonorrhoea and herpes

- No history of diabetes

- Non-smoker (Baylor Scott and White Health 2017).

It is interesting to note the variations in these criteria. A potential recipient has much more to prove than simply having been born without a uterus. Some of these requirements in fact seem to have little to do with the biological condition of lacking a uterus, at all. This, it has been argued, is unfair (Murphy 2015): if a woman should be eligible for uterus transplant because she was born without a uterus, then transwomen, all of whom were born without a uterus, should be an obvious category to be included here. Moreover, some men might genuinely wish to experience pregnancy: why would women's longing to experience pregnancy be worthy of considerable expense and not men's?

One obvious answer might be risk. It is easy to assume that to circumvent the natural biological boundaries of reproduction will be extraordinarily and excessively risky. However, when one examines the question more closely it becomes evident that risk cannot be the whole answer here. For one thing, uterus transplantation in itself is extremely risky. When live donation is undertaken, significant medical harms are imposed on two previously healthy women. Although transplantation to a male body would indeed be complex, it is not obvious that it would be so much riskier than female-to-female transplantation that it cannot be countenanced. One of the teams involved in the recent transplant trials commented that they had foreseen possible interest from the trans community - and had deliberately drawn up their protocol so as to exclude its members despite the fact that they admitted such transplants would be feasible (Grady 2015). 
Expectations of what is 'natural' for a woman and a man (and what is or is not a 'genetic female'), respectively, determine whose desires will be appreciated and will motivate research efforts. Furthermore, one could claim that the fact that the pain and suffering caused by pregnancy only befall women is a natural inequality that we should aim to correct (Smajdor 2007; 2012): this would provide yet another motivation for also pursuing research aimed at providing uterus transplants for men.

An alternative angle might be that reproductive technologies should be used only to recreate specific sorts of relationships between the child and the parent, which IVF fulfils (within the nuclear family parameters), but reproductive cloning or womb transplants for men do not. An associated concern may be that some interventions do not really meet a medical need, while others do: for example, if a treatment is being offered to someone who is biologically infertile, as opposed to someone who is not (The Lancet 2001). This distinction is tricky, however, as we will see in our next section, because infertility itself is defined in a particular way that may exclude medical conditions in single individuals but include unexplained nonconception in heterosexual couples. We will show how applying such criteria could help to pick out some possibilities while excluding others.

\section{Defining infertility}

The WHO defines infertility as a disease of a sexually active couple. Thus, infertility is 'a disease of the reproductive system defined by failure to achieve a clinical pregnancy after 12 months or more of regular unprotected sexual intercourse' (Zegers-Hochschild et al. 2009). What is implicit in this definition is that the unprotected sexual intercourse here is heterosexual. Clearly, a same-sex couple will not achieve a clinical pregnancy, however many months they have unprotected sexual intercourse. The heterosexual couple should in the natural course of events be able to achieve a pregnancy in this way. This way of defining infertility may not be consistent with intuitions about what infertility is. For example, if Jane lacks ovaries, we might think of her as being infertile. However, she is not infertile according to the WHO's current definition - unless she has had unprotected sexual intercourse with a man over the duration of twelve months.

The WHO's definition is influential in determining how infertility is defined in specific countries. For example, in the UK, the National Institute for Health and Care Excellence includes the following recommendation: 'A woman of reproductive age who has not conceived after 1 year of unprotected vaginal sexual intercourse, in the absence of any known cause of infertility, should be offered further clinical assessment and investigation along with her partner' (2013). Because a requisite period of heterosexual intercourse is often a criterion of access to fertility treatment as well as to the medical investigations that precede any intervention, unless she fulfils this condition, she might not even find out that she lacks ovaries. Accordingly, the eligibility of patients (i.e. their need for treatment) has come to be 
dictated in part by a social factor rather than a clinical one: whether or not the patient is infertile depends on whether she has a particular sort of relationship. Provided that claimants are heterosexual, a construction of need can be mapped onto the underlying biological norm.

Clearly, though, it is possible that a lesbian or single woman could suffer from blocked fallopian tubes, or any other reproductive pathology. However, the reproductive pathology is implicitly of lesser importance than the structure of the relationship within which the patient finds herself. In practice, while in some countries definitions such as the WHO one cited above have been amended to allow same-sex couples or single individuals access to fertility treatments, in others they have been made more restrictive to include e.g. the provision that the members of the couple have to be married or cohabit, and of a certain age (not too old).

According to French law:

the object of reproductive medical assistance is to remedy the infertility of a couple or to avoid the transmission to the child or a member of the couple, of a disease of particular gravity. The pathological character of infertility has to be medically diagnosed. The man and the woman have to be alive, of reproductive age, and had previously consented to the embryo transfer or the insemination. (Loi n 2011-814)

Likewise, Italian law restricts eligible infertility to infertility in heterosexual couples. The purpose of assisted reproductive technologies (ARTs) is to 'help solve the reproductive problems caused by human sterility or infertility ... when there are no other therapeutic means to remove the causes of sterility or infertility' (Legge 40, 2004, art. 1). However, the law specifically stipulates that access to such technologies is limited to 'adult couples of different sex, married or cohabiting, of reproductive age, both living' (Legge 40, 2004, art. 5).

A draft bill recently proposed in India would see access to surrogacy restricted to heterosexual couples married for at least five years (Srivastaval 2016). This preference for the (preferably married or at least cohabiting) heterosexual couple, in addition to its natural, assumed procreative potential, has been viewed as essential for the interests of the child: as we have seen above, this interest has been invoked in UK regulations of access to fertility treatment. It is assumed to be in children's interests to have a mother and a father. A growing body of empirical research indicating that what matters most for children's well-being seems to be the quality of family relationships rather than family form (Golombok 2015) is at odds with these expectations. Specifically, the 'no difference' outcome for children from being raised by same-sex as opposed to different-sex parents has been deemed to have reached consensus in the literature (Adams and Light 2015). Hence, if it is the interests of children that is the paramount concern here, directing research and treatment preferably or uniquely towards fulfilment of heterosexual partners' desires is questionable. The UK's requirement in terms of a child's 
need for a father was removed in 2008 - following decades of controversy. The belief of the members of the Warnock Report, that being raised by a mother and a father is better for children, is understandable in the context of its time and pre-dates relevant findings from empirical research: however, three decades on, the same belief has become much harder to support.

The disease of infertility, as defined above, is contextual to a degree far greater than most other diseases. Fertility treatments do not aim at restoring the capacity to achieve a pregnancy via sexual intercourse. Indeed, having become a parent via fertility treatments, one might not have reproduced at all (if gamete donors were used), and at the end of the treatment a couple might be just as incapable of achieving a clinical pregnancy as before. Simone Bateman (2002) argues that medicine should only seek to correct medical pathologies. Another perspective is taken by Habbema et al. (2004) who suggest that it is the symptom of non-conception that is addressed by fertility treatment. However, although non-conception can be a symptom which is treated in fertility medicine, it is not always necessarily the main symptom which brings people to the clinic. For example, those who want to use pre-implantation genetic diagnosis (PGD) or mitochondrial transfer to avoid having a child with a particular gene or a mitochondrial condition may be very well able to reproduce unaided. It is just that they cannot have the sort of child they want, with the person they want to have it with, without medical help.

If we consider whether there $i$ a specific necessary symptom associated with all claimants for fertility treatment, it becomes evident that there is a shared feature: the aspiration to have a (specific kind of) child (Smajdor and Cutas 2015). A woman may have blocked fallopian tubes for years but not become aware of this until she decides to reproduce. The suffering of infertility is dependent on having a specific desire. It is the desire that is treated, regardless of whether the patient is suffering from a reproductive pathology. Without this desire, infertility does not require treatment: on the contrary, it is convenient. Since it is the reproductive aspiration that is treated, and if family form is not determinative of children's well-being, then there seems to be no reason why heterosexual couples' reproductive aspirations should count as medical needs any more than those of other categories of individuals.

\section{Conclusion}

Embedded and unquestioned assumptions about reproduction, fertility and the family determine whose claims and whose suffering deserve attention. Widely shared beliefs, in their turn, contribute to this effect, and legal and professional regulations solidify it. As access to research and clinical trials can be influenced by these unquestioned assumptions, we can see the ongoing cycle of normative assumptions that feed into notions of need, which then generate treatments, for which eligibility is constrained by norms, which 
are then contested - partly on the basis of the new possibilities that have emerged.

The relationships between reproduction, family, medical need and research, are such as to grate against one another. Each new possibility poses new challenges to the ways in which we conceptualise the family. One possible response to this is to attempt to enforce and solidify normative expectations about the family and appropriate roles within it, and to protect it from the threats of innovation. Another might be to ask whether the nuclear family really merits such concern and protection - in a way in which other family types do not. We hope in this chapter to have highlighted some of the tensions between, on the one hand, science's potential to undermine assumptions and expectations in the realm of family-making, and on the other, the potential of these assumptions and expectations to influence the direction of research.

\section{References}

Adams, J., and Light, R. (2015), 'Scientific consensus, the law, and same sex parenting outcomes', Social Science Research, 53: 300-10.

Barrett, M., and McIntosh, M. (1991), The Anti-Social Family, London: Verso.

Barritt, J., Brenner, C. A., Malter, H. E. et al. (2001), 'Mitochondria in human offspring derived from ooplasmic transplantation', Human Reproduction, 16.3: 513-16.

Bateman, S. (2002), 'When reproductive freedom encounters medical responsibility: changing conceptions of reproductive choice', in E. Vayena, P. J. Rowe and P. D. Griffin (eds), Current Practices and Controversies in Assisted Reproduction: Report of a WHO Meeting, Geneva: World Health Organization, 320-32.

Baylor Scott and White Health (2017), 'Womb transplantation', baylorhealth.com/ Advancing Medicine/Areas OfResearch/Transplantation/Pages/ WombTransplantation.aspx (last accessed February 2017).

Bennett, B. (2008), Health Law's Kaleidoscope: Health Law Rights in a Global Age, Aldershot: Ashgate.

Brigham, K. B., Cadier, B., and Chevreul, K. et al. (2013), 'The diversity of regulation and public financing of IVF in Europe and its impact on utilization', Human Reproduction, 1.28.3: 666-75.

Collier, R. (1999), 'Men, heterosexuality and the changing family: (re)constructing fatherhood in law and social policy', in G. Jagger and C. Wright (eds), Changing Family Values, London: Routledge, 38-58.

Cutas, D., and Chan, S. (eds) (2012), Families - Beyond the Nuclear Ideal, London: Bloomsbury.

Deech, R., and Smajdor, A. (2007), From IVF to Immortality, Oxford: Oxford University Press.

Diduck, A., and Kaganas, F. (2012), Family Law, Gender and the State. Text, Cases and Materials, Oxford: Hart.

Golombok, S. (2015), Modern Families. Parents and Children in New Family Forms, Cambridge: Cambridge University Press. 
Grady, D. (2015), 'Will uterine transplants make male pregnancy possible?', New York Times, 16 November, www.nytimes.com/2015/11/16/insider/willuterine-transplants-make-male-pregnancy-possible.html (last accessed May 2017).

Guardian (2015), 'Baby born from grandmother's donated womb', 25 August, theguardian.com/society/2015/aug/25/baby-born-from-grandmothers-donatedwomb (last accessed March 2017).

Habbema, J. D., Collins, J., and Leridon, H. et al. (2004), 'Towards less confusing terminology in reproductive medicine: a proposal', Fertility and Sterility, 82.1: $36-40$.

Hamzelou, J. (2016), 'Exclusive: World's first baby born with new "3 parent" technique', New Scientist, 27 September, www.newscientist.com/article/210721 9-exclusive-worlds-first-baby-born-with-new-3-parent-technique (last accessed May 2017).

Hendriks, S., Dancet, E. A., van Pelt, A. M. et al. (2015), 'Artificial gametes: a systematic review of biological progress towards clinical application', Human Reproduction Update, 21: 285-96.

House of Commons Science and Technology Committee (2004-05), Human Reproductive Technologies and the Law. Fifth Report of Session 2004-05, vol. I, HC 7-1, London: Stationery Office.

Jasanoff, S. (2005), Designs on Nature, Princeton, NJ: Princeton University Press.

Lancet (2001), Editorial, 'Biological uncertainties about reproductive cloning', 358.9281: 519 .

Lee, R. G., and Morgan, D. (2001), Human Fertilisation and Embryology, London: Blackstone.

Lefkowitz, A., Edwards, M., and Balayla, J. (2012), 'The Montreal criteria for the ethical feasibility of uterine transplantation', Transplant International, 25.4: 439-47.

Legge 40 (2004), 19 February, camera.it/parlam/leggi/040401.htm (last accessed March 2017).

Loi n ${ }^{2}$ 2011-814 du 7 juillet 2011 relative à la bioéthique, art. 33, legifrance.gouv. fr (last accessed March 2017).

Macrae, F. (2016), 'Britain's first three-parent baby could be born within one year: scientists say the controversial IVF technique is ready for use', Daily Mail, 9 June, www.dailymail.co.uk/sciencetech/article-3631770/Britain-s-three-parent-babyborn-ONE-YEAR-Scientists-say-controversial-IVF-technique-ready-use.html (last accessed May 2017).

May-Panloup, P., Chretien, M. F., and Jacques, C. et al. (2005), 'Low oocyte mitochondrial DNA content in ovarian insufficiency', Human Reproduction, 20.3: 593-7.

Murphy, T. (2015), 'Assisted gestation and transgender women', Bioethics, 29.6: 389-97.

National Bioethics Advisory Commission (1997), Cloning Human Beings: Report and Recommendations, bioethicsarchive.georgetown.edu/nbac/pubs/cloning1/ cloning.pdf (last accessed February 2017).

National Institute for Health and Care Excellence (2013), Clinical Guideline [CG156]. Fertility Problems: Assessment and Treatment (updated 2016), nice.org.uk/ guidance/cg156/chapter/Recommendations\#defining-infertility (last accessed March 2017). 
Pieters, J. (2015), 'Single women routinely refused IVF treatment', NLTimes.nl, 22 July, nltimes.nl/2015/07/22/single-women-routinely-refused-ivf-treatment (last accessed March 2017).

Rasmussen, C. (2004), 'Canada's Assisted Human Reproduction Act: is it scientific censorship, or a reasoned approach to the regulation of rapidly emerging reproductive technologies', Saskatchewan Law Review, 67: 97-135.

Ravelingien, A., and Pennings, G. (2013), 'The right to know your genetic parents: from open-identity gamete donation to routine paternity testing', American Journal of Bioethics, 13.5: 33-41.

Report of the Committee of Inquiry into Human Fertilisation and Embryology (1984), hfea.gov.uk/docs/Warnock_Report_of_the_Committee_of_Inquiry_into_ Human_Fertilisation_and_Embryology_1984.pdf (last accessed March 2017).

Reynier, P., May-Panloup, P., and Chretien, M. F. et al. (2001), 'Mitochondrial DNA content affects the fertilizability of human oocytes', Molecular Human Reproduction, 7.5: 425-9.

Sample, J. (2015), “Three-parent” babies explained: what are the concerns and are they justified?', The Guardian, 2 February, www.theguardian.com/science/2015/ feb/02/three-parent-babies-explained (last accessed May 2017).

Shepherd, R., Barnett, J., and Cooper, H. et al. (2007), 'Towards an understanding of British public attitudes concerning human cloning', Social Science \& Medicine, 65.2: 377-92.

Smajdor, A. (2007), 'The moral imperative for ectogenesis', Cambridge Quarterly of Healthcare Ethics, 1.16: 336-45.

Smajdor, A. (2012), 'In defense of ectogenesis', Cambridge Quarterly of Healthcare Ethics, 21.1: 90-103.

Smajdor, A., and Cutas, D. (2015), 'Will artificial gametes end infertility?', Health Care Analysis, 23.2: 134-47.

Srivastaval, B. (2016), 'Anti-surrogacy bill dashes hopes of aspiring parents', The Times of India, 20 September, timesofindia.indiatimes.com/city/ranchi/Antisurrogacy-bill-dashes-hopes-of-aspiring-parents/articleshow/54418447.cms (last accessed October 2016).

Stacey, J. (2011), Unhitched: Love, Marriage, and Family Values from West Hollywood to Western China, New York: New York University Press.

Szczurek, J. (2013), 'Pursuing the faith: the 616th academic year at the Pontifical University of John Paul II in Krakow', Analecta Cracoviensia, 45: 355-90.

Wellcome Trust (1998), 'Public perspectives on human cloning', Input to Human Genetics Advisory Committee and the Human Fertilisation and Embryology Authority's consultation document, Cloning Issues in Reproduction, Science and Medicine.

WHO (1998), 'Ethical, scientific and social implications of cloning in human health', WHA41.10, 1998, www.who.int/ethics/en/WHA51_10.pdf (last accessed February 2017).

Wolf, D. P., Mitalipov, N., and Mitalipov, S. (2015), 'Mitochondrial replacement therapy in reproductive medicine', Trends in Molecular Medicine, 21.2: 68-76.

Zegers-Hochschild, F. Adamson, G. D., and de Mouzon, J. et al. (2009), 'International Committee for Monitoring Assisted Reproductive Technology (ICMART) and the World Health Organization (WHO) revised glossary of ART terminology', Fertility and Sterility, 92.5: 1520-4. 